\title{
The effect of intergroup competition on group coordination: An experimental study. ${ }^{1}$
}

\author{
Gary Bornstein", Uri Gneezy ${ }^{* *}$, and Rosemarie Nagel ${ }^{* * *}$
}

May 1999

\footnotetext{
${ }^{1}$ This project was supported by the EU-TMR Research Network ENDEAR (FMRX-CT98-0238), and by grants from the Israel Science Foundation (1997-2000) and Dirección General de Investigación Cientifíca y Técnica PB95-0983. Please address correspondence to Gary Bornstein, Department of Psychology, the Hebrew University, Jerusalem 91905, Israel. E-mail: MSGARY@ mscc.huji.ac.il

* Department of Psychology and the Center for Rationality and Interactive Decision Theory, The Hebrew University of Jerusalem.

** Department of Economics, University of Haifa.

**** Department of Economics, University of Pompeu Fabra.
} 
Abstract: We report an experiment on the effect of intergroup competition on group coordination in the minimal-effort game (Van Huyck et al., 1990). The competition was between two 7-person groups. Each player in each group independently chose an integer from 1 to 7 . The group with the higher minimum won the competition and each of its members was paid according to the game's original payoff matrix. Members of the losing group were paid nothing. In case of a tie, each player was paid half the payoff in the original matrix. This treatment was contrasted with two control treatments where each of the two groups played an independent coordination game, either with or without information about the minimum chosen by the outgroup. Although the intergroup competition does not change the set of strict equilibria, we found that it improved collective rationality by moving group members in the direction of higher-payoff equilibria. Merely providing group members with information about the minimal-effort level in the other group was not sufficient to generate this effect.

\section{JEL classification: C72, C91, C92}

Keywords: Non cooperative games, coordination, minimum effort game, intergroup competition, 


\section{The effect of intergroup competition on intragroup coordination: An experimental study.}

\section{Introduction}

Actual group performance typically falls short of its potential performance as estimated from the capabilities of the individual group members. This phenomenon was first documented by Ringelmann (1913), who had students pull on a rope either alone or in groups, and discovered that groups exerted less force than could have been expected from their combined individual efforts. This drop in group production was later confirmed in numerous experiments using a wide variety of tasks (e.g., Latane et al., 1979, Kerr \& Bruun, 1981, Harkins \& Petty, 1982). Group production loss is attributed to two basic phenomena: Free riding (e.g., when they are being evaluated and rewarded as a group, individual group members do not pull as hard as they can; Ingham et al., 1974; Ledyard 1995 and coordination loss (e.g., group members do not pull on the rope at exactly the same time or in exactly the same direction; Steiner, 1972).

The research on group productivity cited above was restricted to single-group settings. However, in many real-life situations the group's payoffs are contingent on its performance relative to that of other groups, rather than on its absolute level of performance. Economic and political competitions are more appropriately modeled as a tug-of-war than as a "contest" of a single group against Nature. Thus, a high-tech firm must be faster than its competitors in developing a new product, and a political party has to rally more support than its opponents, if these groups are to realize their goals. Intergroup competition also takes place between subgroups within the same organization. Internal tournaments between teams -- for example, between profit centers -- are often created so that relative group performance becomes the basis for incentive awards. 
In previous research we demonstrated that intergroup competition increases group productivity by decreasing free riding within the competing groups (Bornstein, Erev, \& Rosen, 1990; Erev, Bornstein, \& Galili, 1993; Bornstein \& Erev, 1994). Similar results were reported by Nalbantian and Schotter (1997), who compared group productivity under different group incentive schemes and found that tournament-based group incentives led to higher outputs than all other mechanisms investigated. The purpose of the present study was to see whether intergroup competition has a similar effect on intragroup coordination.

It is a well-documented fact that in single-group settings coordination often fails to produce socially optimal outcomes. Cooper et al. (1990) studied coordination in twoperson games and showed that, although the equilibria in these games were Pareto-ranked, i.e., both players did better on one of the equilibria than at the other, subjects often coordinated on the less desirable equilibrium. Similar finding were reported by Van Huyck, Battalio, and Beil (1990), who studied the minimal-effort game - an n-person purecoordination game in which there is no conflict of interests among the players.

The minimal-effort game involves several players, each of whom simultaneously chooses an integer from 1 to 7 . The payoff to any player depends on the integer chosen by that player as well as on the minimal number chosen by any of the other players in the group (including the player herself). The payoff parameters are chosen such that all the players have a common interest in a high minimum, but there is a penalty for choosing a number higher than the group's minimum. Specifically, the game has seven strict equilibria, at each of which every player chooses the same integer. However, the equilibrium at which all the players choose 7 results in the highest possible payoff to every player, while the equilibrium at which all the players choose 1 gives each player the lowest payoff. Van Huyck et al. (1990) found that when the game was played repeatedly, with 
the outcome made public after each round, the minimum quickly moved to 1 , despite the common interest of all the players in the equilibrium at which each player chooses 7.

Do group members coordinate better if they compete against another group? To examine this issue, we adapted the van Huyck at al (1990) game in the following way: The game involved two groups, A and B, with seven players in each group. Each player in each group independently chose an integer $\mathrm{e}_{\mathrm{i} \in \mathrm{A}(\mathrm{B})}$ from 1 to 7 . If the minimum chosen in team $A, \min _{A}=\min \left\{e_{i} \in_{A}\right\}$, was larger than the one chosen in team $B, \min _{B}=\min \left\{e_{i \in B}\right\}$, team A won the competition and each of its members was paid according to the original payoff matrix. Members of team $B$ were paid nothing. In case of a tie, $\min _{A}=\min _{B}$, each player in both teams was paid half the payoff in the original matrix (see appendix A).

Introducing competition between the teams does not change the set of strict equilibria. As in the original, single-group game, the best response in the intergroup coordination game is for each player in each team to match the minimal number chosen in her team. Thus, like the single-group game, the intergroup game has seven strict equilibria, with the equilibrium at which all team members choose 7 being the most efficient and the equilibrium at which all players choose 1 being the least efficient.$^{2}$

However, intergroup competition may change the equilibrium on which players coordinate. Schelling (1960) demonstrated that players are often able to coordinate by focusing on aspects of the environment that are ignored by economic models. We surmise that winning (or not losing) the competition against the outgroup might constitute such a focal point. This conjecture is based on our own research (Bornstein \& Ben-Yossef, 1984; Bornstein, Budescu, \& Zamir, 1996), as well as research by others (Schopler \& Insko, 1992), which shows that groups are highly competitive -- much more so than individuals

\footnotetext{
${ }^{2}$ Of course, in addition, there is a large number of weak equilibria in which all the members of the winning team choose the same effort level and at least two players in the losing team choose a lower effort level. Any player in the losing team can change her strategy without affecting her outcome.
} 
under the same structural conditions. However, since none of these experiments dealt specifically with pure coordination problems, substantiating this hypothesis remains an empirical matter. As pointed out by several researchers (e.g., Schelling, 1960; Lucas, 1986; Ochs, 1995), one cannot know what makes an equilibrium focal without studying how individuals actually behave.

To study the effect of intergroup competition on coordination, we conducted an experiment which confronted groups of subjects with the same coordination problem either with or without intergroup competition. Since coordination is a rather subtle issue, in the sense that a wide variety of theoretically irrelevant cues could serve to make an outcome prominent, we had to be particularly careful in designing this comparison. ${ }^{3}$

First, since intergroup competition necessarily involves the co-presence of two distinctly labeled groups, we included two groups in the control condition as well. But rather than competing against each other, each group was engaged in a separate (independent) minimal effort game. This manipulation excludes the possibility that the mere categorization of subjects into groups (Tajfel, 1981), rather than the conflict of interests between the groups, is responsible for any potential effects. Second, following each period of play, subjects in the intergroup competition treatment were informed about the minimal effort chosen in both groups. Therefore, to ensure that this information per se was not affecting their behavior, we included in our design a second control treatment where, in addition to the minimum chosen in their own team, the players were informed about the minimum chosen in the other team. ${ }^{4}$

\footnotetext{
${ }^{3}$ As argued by Roth (1995), “... details of how [coordination] experiments are conducted maybe of considerable importance, even if they concern features of the environment not addressed by existing theories." (p. 12).

${ }^{4}$ Recall that this had no payoff consequences.
} 


\section{Experimental Procedure}

Subjects: The participants were 210 undergraduate students at the University of Pompeu Fabra with no previous experience with the task. Subjects were recruited by campus advertisements offering monetary reward for participating in a decision task. Subjects participated in the experiment in cohorts of 14 .

Procedure: Upon arrival each participant received 500 pesetas for showing up and each was seated in a separate cubicle facing a personal computer. The subjects were given written instructions concerning the rules and payoffs of the game (see appendix 1) and were asked to follow the instructions while the experimenter read them aloud. Then subjects were given a quiz to test their understanding. Their answers were checked by the experimenters and explanations were repeated when necessary. Subjects were told that, to ensure the confidentiality of their decisions, they would receive their payment on an individual basis.

At the beginning of the experiment, the 14 subjects were randomly divided into two equal-sized teams. Subjects played 10 rounds of the game. The number of rounds to be played was made known in advance. In each round each subject had to chose an integer from 1 to 7 . Following the completion of the round, each subject received feedback concerning: (a) the lowest number chosen by the members of her group in that round; (b) her earnings (in pesetas) in this round; and (c) her cumulative earnings. In two of the treatments, subjects also received feedback concerning the lowest number chosen in the outgroup. Each session lasted about 40 minutes with an average payment of 1109 pesetas per subject, including the fixed show-up fee of 500 pesetas (approximately US\$10). Each 14-person cohort took part in one and only one of the three treatments described below:

Intergroup competition (IC): The group with the higher minimum won the competition and each of its members was paid according to the original payoff matrix. 
Members of the losing team were paid nothing. In case of a tie, each player was paid half the payoff in the original matrix (see Appendix A). Following each round, the participants were informed about the minimum chosen in both groups. Six 14-person cohorts took part in the treatment.

No competition (NC): In this treatment the payoff for each player was determined by her own choice and the minimum chosen in her group (see appendix A). The participants were informed only about the minimum chosen by their own group. Three 14-person cohorts took part in the treatment. Since there was no interdependence between the two groups, we obtained 6 independent observations.

No competition with information (NCI): This treatment is identical to the NC above (that is, each of the two groups played an independent coordination game) with one exception; following each round subjects were informed about the minimum of the outgroup in addition to their own group (as was the case in IC experimental treatment). Six 14-person cohorts took part in the treatment.

\section{Results}

Overall effort levels: First we compared the three treatments with regard to the mean effort level per period averaged across the 10 periods of the game. The mean effort level per period was 5.3 in the IC treatment, 3.6 in the $\mathrm{NC}$ treatment, and 3.5 in the NCI treatments. The difference between the IC and the NC treatment is statistically significant by a Wilcoxon rank-test $(z=2.248, p<.0246)$, and so is the difference between the IC and NCI treatment $(z=2.830, p<.0047)$. The difference between the NC and NCI control treatments is not significant.

Convergence: Subjects' initial decisions were unaffected by treatment. The mean effort level in Period 1 was 5.7, 5.6, and 5.5 in treatments IC, NC, and NCI, respectively. These means are not significantly different from one another. Before long, however, 
subjects in the NC and NCI control treatments began reducing their effort level as compared with those in the IC experimental treatment, whose effort level remained, on average, quite stable throughout the 10-period game.

Figure 1 displays the mean choice per period in each of the three treatments. ${ }^{5}$ The difference between the IC treatment and the two control treatments is already visible in Period 3. ${ }^{6}$ From Period 4 onward, the mean effort level in the IC treatment is significantly higher than that in the NC treatment $(z=2.256, p<.0241)$, and from Period 5 onward, it is also significantly higher than that in the NCI treatment $(z=2.831, p<.0046)$. The difference between the NC and NCI control treatments remains insignificant throughout the entire game. ${ }^{7}$

The difference between the intergroup experimental treatment and the single-group control treatments became even more pronounced as the game progressed. The mean effort level in the IC treatment in the tenth and last period was 5.3, more than twice as high than the effort level in the NC and NCI treatments, which was only 2.6 and 2.4, respectively. The difference between the mean choice in the IC treatment and the NC and NCI treatments is, of course, statistically significant $(z=2.817, p<.005$, and $z=3.297$, $p<.0 .001$, respectively).

\footnotetext{
${ }^{5}$ Figure 1 ' in Appendix 2 shows the mean behavior for each group in each session separately.

${ }^{6}$ The mean effort in the third period was 5.1 in the IC treatment, as compared with 4.2 and 4.1 in treatments NC and NCI, respectively.

${ }^{7}$ In this test, as well as in all other tests apart from that of the first period, we considered each (14-person) cohort in treatments IC and NCI and each (7-person) team in treatment $\mathrm{NC}$ as a unit for analysis in order not to violate the independence assumption.
} 


\section{Figure 1: Mean choice}

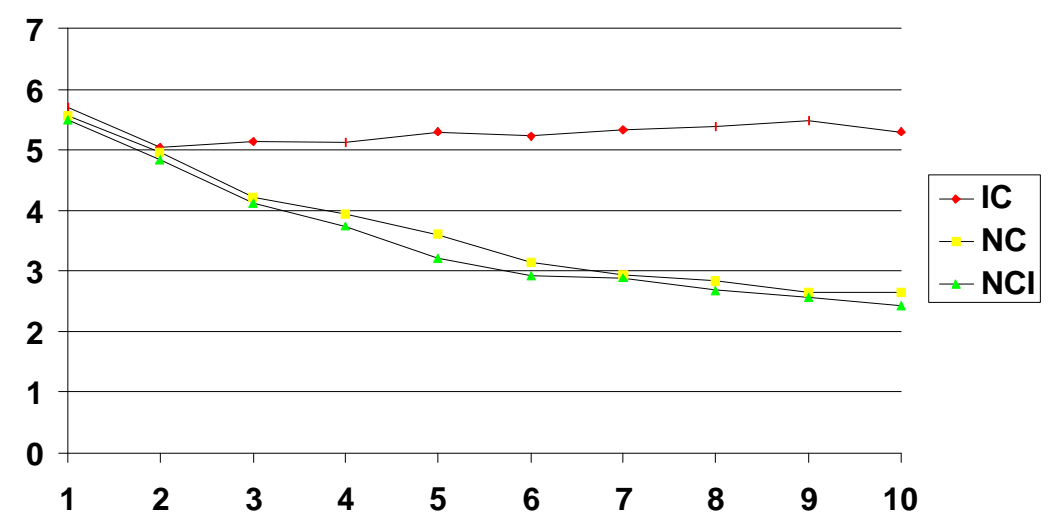

In the first period, approximately half of the subjects chose the highest effort level of 7, while the others chose a lower level, with a modal choice of 4 or 5. A sharp drop in the number of players choosing 7 in round 2 is observed in all treatments. In the IC treatment subjects were able to recover from that drop, and in the final period the distribution of choices is similar to that in the initial period. In the other two treatments, however, there was an almost monotonic decrease in the number of subjects choosing 7 , accompanied by a monotonic increase in the number of subjects choosing 1 .

Minimum effort levels: Next we compared the minimum effort level in the three treatments. The average minimum choice per period in each of the three treatments appears in Figure 2. ${ }^{8}$

\footnotetext{
${ }^{8}$ Figure 2' in the appendix shows the minimum of each group in each session separately.
} 


\section{Figure 2: Minimum choice}

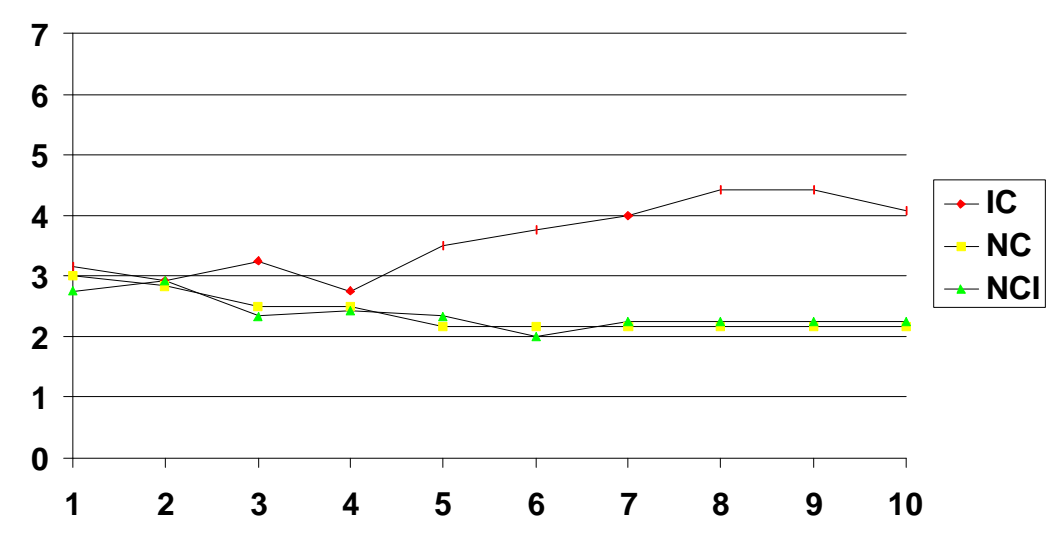

As can be seen in Figure 2, the minimal effort level in the first period is almost identical in the three treatments. ${ }^{9}$ In fact, the mean minimum remains very similar across treatments in the first four periods. Starting with Period 5, however, we observe an (albeit slow) increase in the average minimum in the IC treatment, as compared with a slight decrease in the minimum choice in the other two treatments. The minimum in Period 5 is 3.5, 2.2, and 2.3 in treatments IC, NC, and NCI respectively, and the differences between the IC experimental treatment and the NC and NCI control treatments are statistically significant $(z=-1.93, p<.0 .02 ; z=-1.55, p<0.06$, respectively).

The mean minimum in the last period in treatment IC was 4.1 as compared with 2.2 and 2.25 in treatments NC and NCI, respectively. The differences between the IC treatment and the NC and NCI treatments are statistically significant $(z=-0.203, \mathrm{p}<0.02$,

\footnotetext{
${ }^{9}$ The means in treatments IC, NC, and NCI were 3.2, 3.0, and 2.8, respectively. These means are not statistically different from one another.
} 
$z=-1.85, p<.0 .03$, respectively), while the difference between the two control conditions is not.

Table 1 displays the proportion of times the group minimum decreased, increased, or remained the same from one period to the next as a function of whether the group won, tied, or lost the competition in the previous period.

Table 1: Changes of Minimum

\begin{tabular}{|l|l|l|l|l|}
\hline $\begin{array}{l}\text { Min } \\
\text { Ingroup } \\
\text { Min }=< \\
\text { Min } \\
\text { Outgroup }\end{array}$ & $\begin{array}{l}\text { Change of min } \\
\text { from previous } \\
\text { period }\end{array}$ & IC & NCI & NC \\
\hline$>$ & & & & \\
$>$ & Decrease & 0.23 & 0.10 & \\
$>$ & Unchanged & 0.54 & 0.88 & n.a \\
\hline$=$ & Increase & $\underline{0.23}$ & 0.02 & \\
$=$ & Decrease & 0.20 & 0.15 & \\
$=$ & Unchanged & 0.53 & 0.85 & n.a \\
\hline$<$ & Increase & 0.27 & 0.00 & \\
$<$ & Decrease & 0.23 & 0.15 & \\
$<$ & Unchanged & 0.26 & 0.66 & n.a \\
\hline Increase & 0.51 & 0.20 & \\
\hline Overall & Decrease & 0.22 & 0.13 & 0.15 \\
Overall & Unchanged & 0.44 & 0.78 & 0.79 \\
Overall & Increase & $\underline{0.34}$ & 0.08 & 0.06 \\
\hline
\end{tabular}

As can be seen in the table, the rate of increases in the IC treatment was .23 (5/39) if the group won the last round, $.27(8 / 30)$ if the last round was tied, and $.51(20 / 39)$ if the group lost the previous round. These rates are much higher than those in the NCI treatment, where following a "win", a "tie", and a "loss" the minimum increased at a rate of $.02, .00$, and .20 , respectively. ${ }^{10}$

Assuming that players used a fictitious-play strategy can perhaps explain why (1) the minimum was much more likely to increase in the IC treatment than in the NC and NCI

\footnotetext{
${ }^{10}$ It is interesting to note that the group's minimum in the NCI treatment increased by $20 \%$ when the ingroup was behind in the previous round. Perhaps some of the ingroup players used the (higher) outgroup's minimum as a focal point in an attempt to improve group coordination. In any case, this was not sufficient to generate a steady increase of the minimum over time as was observed in the IC treatment.
} 
treatments, and (2) the rate of increases in the IC treatment was much higher following a loss than following a tie or a win. In the NC and NCI control treatments, if a player assumes that the behavior of all other players remains constant, her optimal response in Period $t+1$ is to select the team's minimum observed in Period t. The same is true in treatment IC, given that the ingroup won or tied the competition in the previous period. Following a loss in the IC treatment, however, a player can choose a higher effort level without affecting her outcome. As was the case in Cachon and Camerer's experiment (1996), there is only one direction in which behavior can be modified to (possibly) improve one's payoffs.

The number of decreases in the IC-treatment was surprisingly high. However $80 \%$ of these decreases occurred in the first 5 rounds. Furthermore, half $(50 \%)$ of the decreases in a given period $(\mathrm{t})$ were caused by players who chose a number higher than their group's minimum in the previous period (t-1). In all but two of these cases (9/11)the players increased their effort level again in the following period $(t+1)$. The behavior of these players can be interpreted as a repeated-game strategy indended to affect the behavior of the other players. The fact that $80 \%$ of their fellow group members did not decrease their effort level to match the new minimum suggests that this strategy was indeed effective. In the NC and NCI-treatment, on the other hand, lowering the minimum in period t caused more than $60 \%$ of the players to reduce their own effort level in period $t+1$. Therefore the minimal effort level almost never increased again.

\section{Conclusions}

Our experiment demonstrates quite clearly that intergroup competition improves coordination in the minimum effort game by moving group members in the direction of the collectively rational equilibria. It also shows that for this to happen the competition must 
have payoff consequences. Merely providing the members of each group with information about the minimal effort level in the other group is not sufficient to generate this effect. In our experiment, the members of the losing team were paid nothing. It remains to be seen whether a milder manipulation, where the members of both teams are paid according to the original matrix regardless of the outcome of the intergroup competition, but the members of the winning team get a fixed bonus (and half that for a tie), can generate this effect.

The existing literature covers a very limited set of means for improving coordination. These include restricting group size (to three players or less), imposing participation costs such that coordinating on some equilibria results in losing money (Van Huyck, Batallio and Beil, 1993 and Cachon and Camerer, 1996), allowing one-sided (but not two-sided) communication (Cooper, Dejong, Forsthye, and Ross 1989) or repeating the game for a large number of periods (Berninghaus and Ehrhart, 1998). The mechanism studied here, namely competition with another group, appears to be considerably more useful as it can be implemented regardless of group size, communication pattern, participation cost, and interaction length.

Intergroup competition or tournament-based reward mechanisms are quite prevalent in economic life. Such competition takes place between different organizations as well as between subgroups within the same organization (e.g., independent profit centers). The group that wins the competition is the one whose members are more cooperative and better coordinated with one another than members of the competing groups. Our results suggests that under these conditions one can expect coordination among group members to be better than what could have expected from the results of single-group experiments. From a policy point of view, it is clearly desirable to introduce competition in contexts where groups still act in isolation. For example, universities in Europe are funded without much regard to their performance relative to that of other universities. Our results, 
together with those of Bornstein \& Erev (1994) and Nalbantian and Schotter (1997), seem to indicate that the performance of these institutions can be greatly improved by endowing them, at least to some extent, on a relative or competitive basis. To use Nalbantian and Schotter's (1997) words, it indeed seems that "a little [intergroup] competition goes a long, long way." 


\section{References:}

Berninghaus, S. K. and Ehrhart, K. M. (1994). Time Horizon and Equilibrium Selection in Tacit Coordination Games: Experimental Results. Journal of Economic Behavior and Organization, $\underline{37}, 231-248$.

Bornstein, G., \& Erev, I. (1994). The enhancing effect of intergroup competition on group performance. International Journal of Conflict Management, $\underline{5}$, 271-284.

Bornstein, G., Erev, I., \& Rosen, O. (1990). Intergroup competition as a structural solution to social dilemmas. Social Behavior, $\underline{5}, 247-260$.

Bornstein, G., \& Ben-Yossef, M. (1994). Cooperation in intergroup and single-group social dilemmas. Journal of Experimental Social Psychology, 30, 52-67.

Bornstein, G., Budescue, D., \& Zamir, S. (1997). Cooperation in intergroup, two-person, and n-person games of Chicken. Journal of Conflict Resolution, 41, 384-406.

Cachon, G. and Camerer (1996). The sunk cost fallacy, forward induction and behavior in coordination games. Quartely Journal of Economics 111, 165-194.

Cooper, R, DeJong, D, Forsythe, R., and Ross, T (1990). Selection Criteria in Coordination Games: Some experimental results. American Economic Review 80:218-33.

Cooper, Dejong, Forsthye, and Ross (1989). Communication in Coordination Games. Working paper Series 89-16. College of Business Administration, University of Iowa.

Erev, I., Bornstein, G., \& Galili, R. (1993). Constructive intergroup competition as a solution to the free rider problem: A field experiment. Journal of Experimental Social Psychology, 29, 463-478.

Harkins, S. G., \& Petty, R. E. (1982). Effects of task difficulty and task uniqueness on social loafing. Journal of Personality and Social Psychology, 43, 1214-29.

Ingham, A. G., Levinger, G., Graves, J., \& Peckham, V. (1974). The Ringlemann effect: Studies of group size and group performance. Journal of Experimental Social Psychology, $\underline{10}, 371-84$.

Kerr, N. \& Bruun, S. (1981). Ringlemann revisited: Alternative explanations for the social loafing effect. Personality and Social Psychology Bulletin, $\underline{7}, 224-31$.

Latane, B., Williams, K., \& Harkins, S. (1979). Many hands make light the work: The causes and consequences of social loafing. Journal of Personality and Social Psychology, $\underline{37}, 822-32$.

Lucas, R. E. (1986). Adaptive behavior and economic theory. In Rational choice: the contrast between economics and psychology, R. Hogarth and M. Reder, editors, Chicago: University of Chicago Press. 217-42. 
Nabantian, H. R., \& Schooter, A. ( 1997). Productivity under group incentives: An experimental study. American Economic Review, 87, 314-341.

Ochs, J. (1995). Coordination Problems. In Handbook of experimental economics. Eds. A. Roth and J. Kagel, Princeton University Press, Princeton.

Renglemann, M. (1913). Recherches sur les moteurs animes: Travail de l'homme. Annales de l'Institut National Agronomique, 12, 1-40.

Schelling, T. (1960). The strategy of conflict. Cambridge, mass.: Harvard University Press.

Schopler, J., \& Insko, C. (1992). The discontinuity effect in interpersonal and intergroup relations: Generality and Mediation. European Review of Social Psychology, $\underline{3}, 121-51$.

Steiner, I. D. (1972). Group Processes and Productivity. New York: Academic Press.

Tajfel, H. (1982( Social psychology of intergroup relations. Annual Review of Psychology, 33, 1-39.

Van Huyck, J., R. Battalio, and R. Beil (1990). Tacit coordination games, strategic uncertainty, and coordination failure. American Economic Review, 80, 234-48.

Van Huyck, Batallio and Beil (1993). Asset markets as an euqilibrium selection mechanism. Games and Economic Behavior, 5, 485-504.Bornstein, G., \& Erev, I. (1994). The enhancing effect of intergroup competition on group performance. International Journal of Conflict Management, $\underline{5}, 271-284$. 


\section{Appendix 1}

\section{Instructions (intergroup treatment):}

This is an experiment on the economics of decision-making. Your earnings will depend on your own decision and the decisions of the other participants. You will be paid in cash at the end of the experiment. Please read the instructions carefully. The instructions are identical for all the participants in the room. If you have a question raise your hand and the instructor will come over and answer your question in private. Please do not communicate from now on with the other participants.

The rules: The experiment consists of 10 rounds. At the beginning you will be divided into two groups of seven players. The groups will stay the same for all ten rounds of the experiment.

Each participants has to choose a number from 1 to $7\{1,2,3,4,5,6,7\}$ in each of the 10 rounds. In each round the smallest number chosen in each group will be identified.

Your payoff depends upon your own choice, the smallest number chosen by the participants in your group and the smallest number chosen by the participants of the other group. More specifically, the group with the smaller of the two smallest numbers wins 0 points, while the participants in the group with the larger of the smallest numbers win points according to the table. In case of a tie, the payoff table will be split evenly, with each cell being divided by 2 .

Here is the payoff table: smallest number chosen by the participants in your group

\begin{tabular}{ll|lllllll}
\hline \multirow{5}{*}{$\begin{array}{l}\text { your } \\
\text { decision }\end{array}$} & 7 & 7 & 6 & 5 & 4 & 3 & 2 & 1 \\
& 6 & 130 & 110 & 90 & 70 & 50 & 30 & 10 \\
& 5 & - & 120 & 100 & 80 & 60 & 40 & 20 \\
& 4 & - & - & 110 & 90 & 70 & 50 & 30 \\
& 3 & - & - & - & 100 & 80 & 60 & 40 \\
& 2 & - & - & - & - & 90 & 70 & 50 \\
& 1 & - & - & - & - & - & 80 & 60 \\
& 1 & - & - & - & - & - & 70
\end{tabular}

Let us explain the table. If the smallest number in your group is higher than that of the other group, your points in each round depend on your own choice (indicated by the first column of the table "your decision", $7,6, \ldots, 1)$ ) and the smallest number chosen in your group, including your number (indicated by the first row of the table $7,6,5, \ldots 1$ ). Since your choice can be a number from 1 to 7 , the smallest number can be range from 1 to 7 . Your points are determined by the cell in the row of your decision and the column of the smallest number in your group. An example is given below.

In the table there are cells with "“-“. This indicates that a combination of your choices and the smallest chosen number in your group is not possible. For example, if your decision is 4 , the smallest number in your group cannot be 7,6 , or 5 .

Remember that if both groups have the same smallest number then the cell which determines your payoff is divided by 2. If the smallest number chosen in your group is smaller than that of the other group, you will win 0 points.

\section{Examples:}

If the smallest number in your group is higher than that of the other group and

-- you chose 3 and the smallest number in your group was 3, you win 90 points (row " 3 " and column "3").

-- you chose 5 and the smallest number in your group was 3 , you win 70 points (row " 5 " and column " 3 ").

-- you chose 5 and the smallest number in your group was 4, you win 90 points (row " 5 " and column " 4 ").

-- you chose 4 and the smallest number in your group was 1 , you win 40 points (row " 4 " and column " 1 ").

-- you chose 3 the smallest chosen number in your group cannot be 4 (there is a - in row " 3 " and column

"4."). 
-- you chose 7 and the smallest number in your group is 4, your points are (WRITE DOWN YOUR POINTS).

If the smallest numbers in both groups are the same and

-- you chose 5 and the smallest number in both groups is 4 , you win 45 points (row " 5 ", column " 4 ", points $90 / 2$ ).

-- you chose 4 and the smallest number in both groups is 1 , you win 20 points (row "4", column "1", points 40/2).

-- you chose 6 and the smallest number in both groups is 3, you win (WRITE DOWN YOUR

POINTS).

Information following each round: Following each round you will be informed about the smallest number of your group, the smallest number in the other group, your own payoff and your accumulated payoffs in the rounds completed so far. We also remind you of your own choice.

Computer screen: On the middle of the screen you will find 7 buttons labeled from 1 to 7 . You can indicate your choice by a mouse-click on one of the buttons or by pressing the corresponding key from 1 to 7. You will then be asked whether you "are sure" about this choice. If you click Yes with the mouse or press the key Y the choice will be final. If you click No with the mouse or press N, you return to the window to make your choice again. After you have made your decision, please wait until all the other participants have completed their choices.

At the top of the screen you will find the results of the current period, with your decision, the smallest number chosen in your group, the smallest number chosen in the other group, your payoff for that period, and the cumulative payoffs of the rounds completed so far.

Payments: At the end of the experiment all your cumulative points will be converted into pesetas with 1 point being $\mathrm{x}$ pesetas, thus if you have made 10 points you will receive $\mathrm{x} * 10$ pesetas.

If you have any question please raise your hand. 


\section{Instructions (single-group treatment):}

This is an experiment on the economics of decision-making. Your earnings will depend on your own decision and the decisions of the other participants. You will be paid in cash at the end of the experiment. Please read the instructions carefully. If you have a question raise your hand and the instructor will come over and answer your question in private. Please do not communicate from now on with the other participants.

The rules: The experiment consists of 10 rounds. At the beginning you will be divided into two groups with seven participants. The groups will stay the same for all ten rounds of the experiment.

Each participant has to choose a number from 1 to $7\{1,2,3,4,5,6,7\}$ on each of the 10 rounds. In each round the smallest number chosen in each group will be identified. Your payoff is determined according to the following payoff table:

smallest number within your group

\begin{tabular}{|c|c|c|c|c|c|c|c|c|}
\hline \multirow{8}{*}{$\begin{array}{l}\text { your } \\
\text { decision }\end{array}$} & & 7 & 6 & 5 & 4 & 3 & 2 & 1 \\
\hline & 7 & 130 & 110 & 90 & 70 & 50 & 30 & 10 \\
\hline & 6 & - & 120 & 100 & 80 & 60 & 40 & 20 \\
\hline & 5 & - & - & 110 & 90 & 70 & 50 & 30 \\
\hline & 4 & - & - & - & 100 & 80 & 60 & 40 \\
\hline & 3 & - & - & - & - & 90 & 70 & 50 \\
\hline & 2 & - & - & - & - & - & 80 & 60 \\
\hline & 1 & - & - & - & - & - & - & 70 \\
\hline
\end{tabular}

Let us explain the table: Your points in each round depend on your own choice (indicated by the first column of the table "your decision" $7,6, \ldots, 1)$ ) and the smallest number chosen in your group, including your number (indicated by the first row of the table $7,6,5, \ldots 1$ ). Since your choice can be a number from 1 to 7 , the smallest number can range from 1 to 7 . Your points are determined by the cell in the row of your decision and the column of the smallest number in your group. An example is given below.

In the table there are cells with “-“. This indicates that a combination of your choices and the smallest chosen number in your group is not possible. For example, if your decision is 4 , the smallest number in your group cannot be 7,6 , or 5 .

\section{Examples:}

-- you chose 3 and the smallest number in your group was 3, you win 90 points (row " 3 " and column " 3 ") -- you chose 5 and the smallest number in your group was 3 , you win 70 points (row " 5 " and column " 3 ") -- you chose 5 and the smallest number in your group was 4, you win 90 points (row " 5 " and column "4") -- you chose 4 and the smallest number in your group was 1 , you win 40 points (row " 4 " and column " 1 ") -- you chose 3 then smallest chosen number in your group cannot be 4 (there is a - in row " 3 " and column "4.")

-- you chose 7 and the smallest number in your group is 4, your points are

\section{(WRITE DOWN YOUR POINTS)}

Information following each round: Following each round you will be informed about the smallest number of your group, your own payoff and your accumulated payoffs for the rounds completed so far. We will also remind you of your own choice.

Computer screen: On the middle of the screen you will find 7 buttons labeled from 1 to 7 . You can indicate your choice by a mouse-click on one of the buttons or by pressing the corresponding key from 1 to 7. You will then be asked whether you "are sure" about this choice. If you click Yes with the mouse or press the key $\mathrm{Y}$ the choice will be final. If you click No with the mouse or press N, you return to the window to make your choice again. After you have made your decision, please wait until all the other participants have completed their choices. 
At the top of the screen you will find the results of the current period with your decision, the smallest number chosen in your group, your payoff for that period, and the cumulative payoffs in the rounds completed so far.

Payments: At the end of the experiment all your cumulative points will be converted into pesetas with 1 point being $\mathrm{x}$ pesetas, thus if you have made 10 points you will receive $\mathrm{x} * 10$ pesetas.

If you have any questions please raise your hand. 
Appendix 2

Figure 1': Mean behavior over time in each group and session. Session 1-6 are IC sessions, session 7-9 are NC sessions and sessions 10-15 are NCI sessions

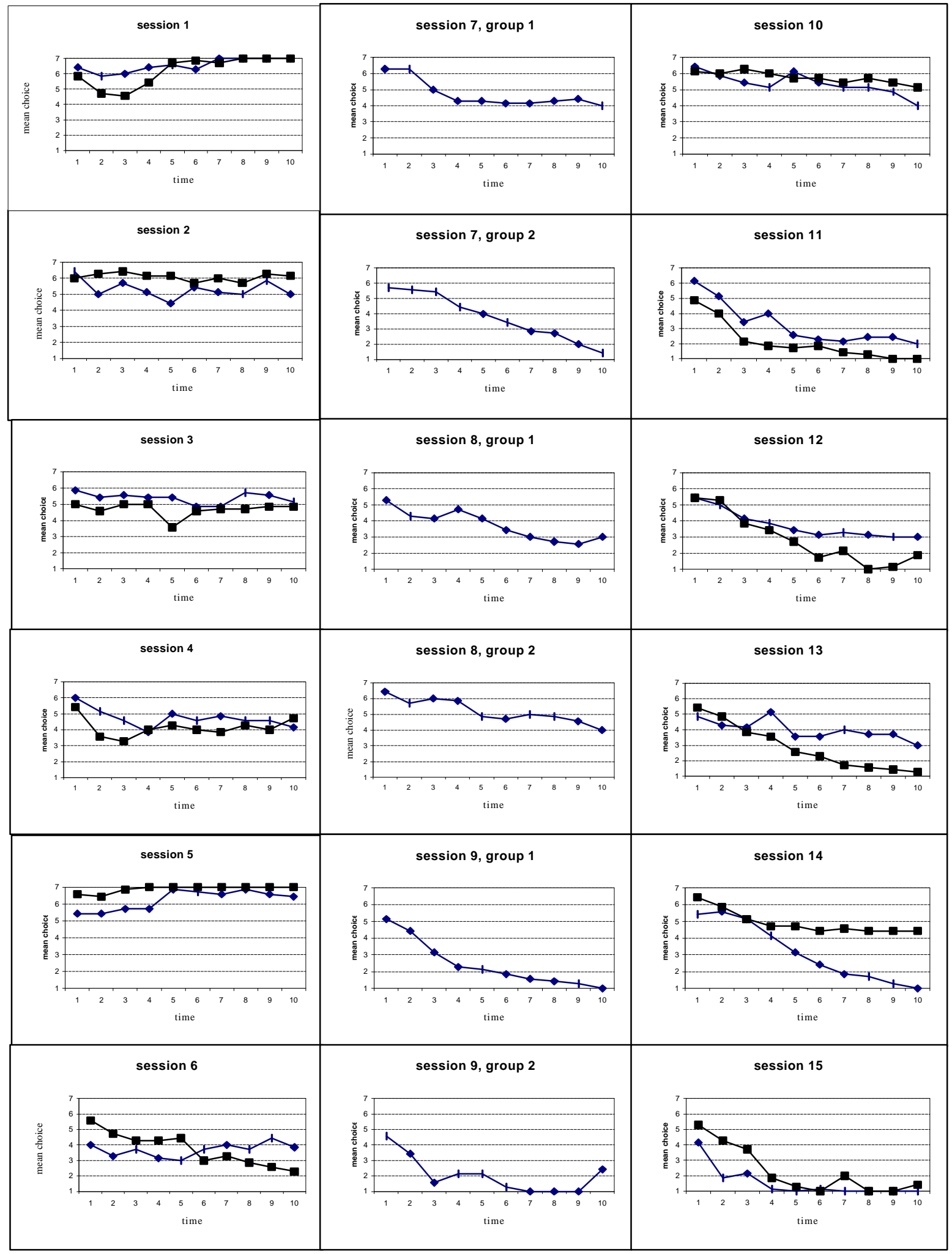


Figure 2': Minimum behavior over time in each group and session. Session 1-6 are IC sessions, session 79 are NC sessions and sessions 10-15 are NCI sessions

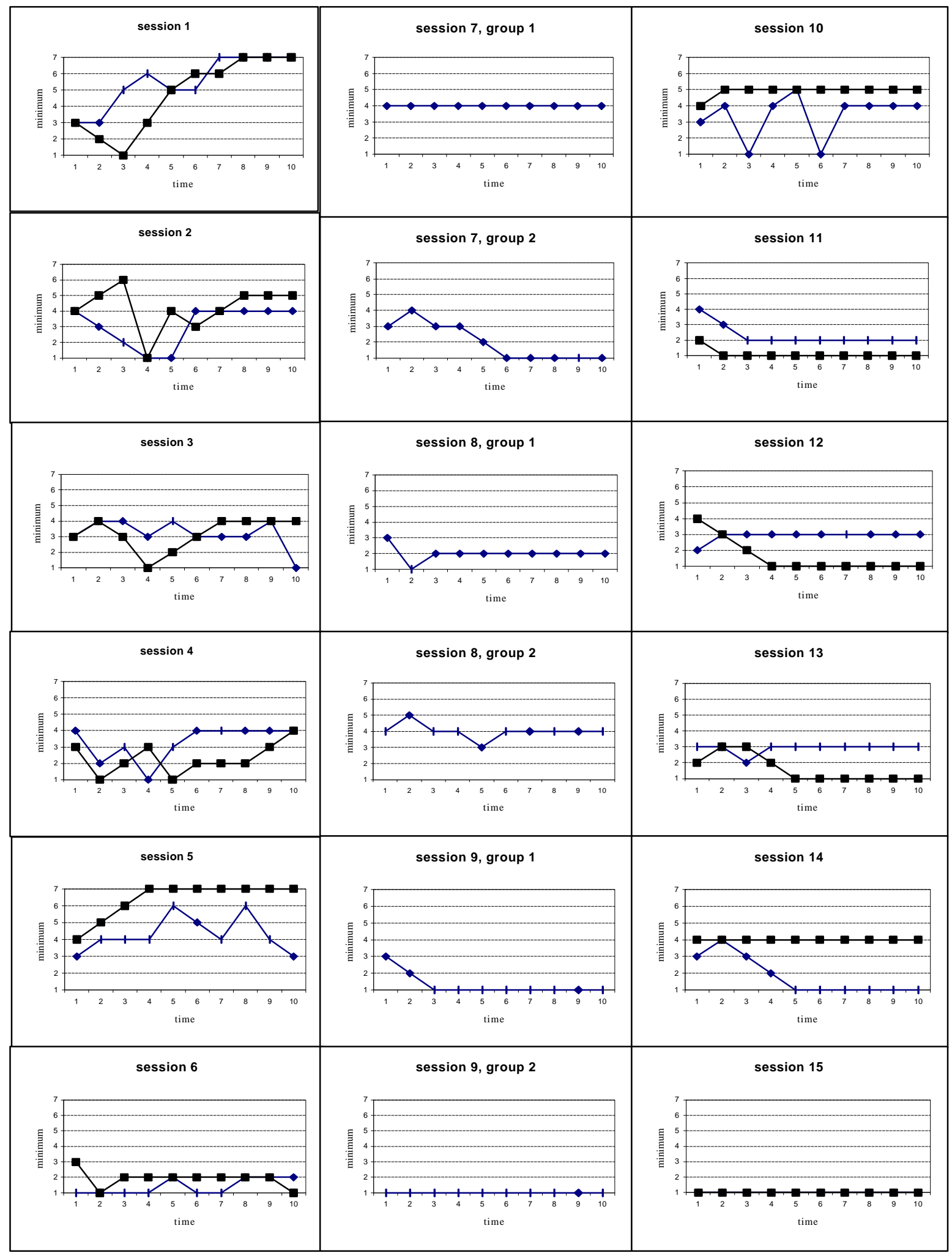

